\title{
Effect of Synthesis Conditions on Crystal Morphology and Layer Thickness of Nanostructured Sodium Niobate Supported on Metallic Substrate
}

\author{
Beatriz Rodrigues Canabarro (iD) and Paula Mendes Jardim \\ Department of Metallurgical and Materials Engineering, Federal University of Rio de Janeiro, 68505 RJ, Brazil \\ Correspondence should be addressed to Beatriz Rodrigues Canabarro; canabarro@metalmat.ufrj.br
}

Received 29 September 2018; Revised 7 November 2018; Accepted 21 November 2018; Published 16 December 2018

Academic Editor: Fernando Rubio-Marcos

Copyright (c) 2018 Beatriz Rodrigues Canabarro and Paula Mendes Jardim. This is an open access article distributed under the Creative Commons Attribution License, which permits unrestricted use, distribution, and reproduction in any medium, provided the original work is properly cited.

\begin{abstract}
Sodium niobate presents numerous interesting properties for technological application and can be produced in nanometric structures if synthesized by alkali hydrothermal route. Although the influence of synthesis conditions on the product morphology and crystal structure has been well explored for niobates synthesized from the powder of niobium oxide, the synthesis on metallic niobium platelets is not completely understood. Therefore, the present study seeks to correlate the synthesis' variables, of alkali hydrothermal route, to morphology and thickness of sodium niobate nanowire layer supported on niobium platelets. An experimental design was planned to evaluate whether temperature, alkali solution concentration, and reactional duration influence on the produced materials. The morphology of $1 \mathrm{D}$ niobates produced was investigated by scanning, while crystal structure was analyzed by X-ray diffraction. The cross sections of $1 \mathrm{D}$ sodium niobate layers were cut with a focused ion beam, and their thickness was quantified by scanning electron microscopy images. It was concluded that all chosen variables influenced the thickness of the sodium niobate layer, and a model describing the layer thickness with the chosen variables was proposed. A morphology change from nanowires at the mildest synthesis conditions to nanoribbons at the most severe ones was observed (see Supplementary Material for graphical abstract).
\end{abstract}

\section{Introduction}

Alkali niobates have gained scientific and technological interest due to their properties as a piezoelectric, nontoxic, pyroelectric, photocatalytic material among others, and their wide range of possible applications $[1,2]$. Their nontoxicity and bioactivity motivated studies related to a possible application as a biomaterial for implants $[3,4]$. On the contrary, the combination of piezoelectricity with photoactivation showed an improvement in their photocatalytic performance [5]. The photocatalytic properties strongly depend on the material crystal structure and morphology; therefore, their formation and growth comprehension are important steps for the design of new and efficient materials for this purpose [6-9].

Sodium niobate was first studied in 1896, by Holmquist, when it was synthesized through solid-state route, from $\mathrm{Na}_{2} \mathrm{CO}_{3}$ and $\mathrm{Nb}_{2} \mathrm{O}_{5}$ powders at high temperature $\left(1500^{\circ} \mathrm{C}\right)$, obtaining crystals with $\mathrm{NaNbO}_{3}$ stoichiometry, cubic-like shape, and orthorhombic crystal structure [10]. The synthesis of sodium niobate can also be made by the hydrothermal route. This method turned possible the production of this material with the same stoichiometry at the nanoscale, with rapid nucleation and epitaxial growth, which led to the formation of single crystals with nanowire shape. These nanowires showed a different crystal structure (monoclinic) that was labeled as a hydrated sodium niobate, showing $\mathrm{Na}_{2} \mathrm{Nb}_{2} \mathrm{O}_{6} \cdot \mathrm{H}_{2} \mathrm{O}$ formula [11-14]. After that, it was discovered that this was a metastable compound that could be transformed into orthorhombic $\mathrm{NaNbO}_{3}$ either by increasing hydrothermal reaction time but losing the $1 \mathrm{D}$ morphology, or through heat treatment, with the maintenance of the wire format $[11,15]$.

The hydrothermal synthesis' method has shown promise in manufacturing niobates, both from niobium oxides $[1,6,11,12,16-19]$ and from the metallic niobium $[4,15]$. 
This route requires much lower temperatures than those of the solid-state reaction and also enables the obtainance of crystals in the nanometric scale $[17,20,21]$. Studies have shown that the variation in the hydrothermal synthesis conditions, such as temperature, alkali concentration, and precursor, among others, can influence the growth mechanism of the nanomaterials produced and consequently modify their morphology [15, 19, 22-24]. Although there are several studies about the hydrothermal synthesis of niobates from the powder of niobium oxide $[9,11,17]$, there is none information in the literature related to the quantitative influence of synthesis conditions using metallic niobium as a precursor.

Therefore, the aim of the present study is to investigate how the synthesis variables influence the formation of sodium niobate crystals produced from metallic niobium, by hydrothermal synthesis using aqueous $\mathrm{NaOH}$ solution. With this intent, an experimental design was made, using three variables in two conditions and three central points. The chosen entrance variables were temperature, reaction duration, and aqueous $\mathrm{NaOH}$ concentration, and these variables' effects on the nanostructured 1D niobates morphology and layer thickness were evaluated.

\section{Materials and Methods}

2.1. Sodium Niobate Synthesis. The sodium niobate layer was synthesized on metallic niobium by the hydrothermal method followed by annealing treatment. Initially, the niobium substrates with a thickness of $0.1 \mathrm{~cm}$ were cut, with the dimension of $1 \mathrm{~cm} \times 1 \mathrm{~cm}$, grounded, then cleaned, in an ultrasonic bath with deionized water for 20 minutes, and dried at atmospheric conditions. Three of these niobium platelets were placed in the bottom of a Teflon-lined $500 \mathrm{~mL}$ autoclave filled with $150 \mathrm{~mL}$ of $\mathrm{NaOH}$ solution. The synthesis was performed under different conditions according to the experimental design. After synthesis, the samples were washed with deionized water, dried at $100^{\circ} \mathrm{C}$, and then annealed in a vacuum furnace at $550^{\circ} \mathrm{C}$ for 15 minutes to convert $\mathrm{Na}_{2} \mathrm{Nb}_{2} \mathrm{O}_{6} \cdot \mathrm{H}_{2} \mathrm{O}$ (monoclinic) to $\mathrm{NaNbO}_{3}$ (orthorhombic).

2.2. Experimental Design. In this study, a single-replicate of a full $2^{k}$ factorial design with three center points was applied to evaluate the synthesis variables' influence on the thickness of the sodium niobate layer, such as temperature, duration of synthesis, and alkali concentration. These three variables were chosen to complete a factorial experimental plan of $2^{3}$ with three center points (Table 1). The maximum and minimum values of the variables were chosen so that the correspondent center points of the chosen variables were according to those in the study of Grange et al. [2]. The order of the synthesis conditions was randomized (Table 2), intending to avoid any kind of influence that was not connected to the chosen variables.

In order to simplify the presentation of the conditions used in each sample, it will be used a notation presented in Table 2 , represented by time (h)-temperature $\left({ }^{\circ} \mathrm{C}\right)-\mathrm{NaOH}$
TABle 1: Experimental levels of the factors chosen at the experimental design.

\begin{tabular}{lcccc}
\hline Factor & Symbol & $\begin{array}{c}\text { Maximum } \\
(+)\end{array}$ & $\begin{array}{c}\text { Central } \\
(0)\end{array}$ & $\begin{array}{c}\text { Minimum } \\
(-)\end{array}$ \\
\hline Time & $\mathrm{A}$ & $12 \mathrm{~h}$ & $24 \mathrm{~h}$ & $36 \mathrm{~h}$ \\
Temperature & $\mathrm{B}$ & $40^{\circ} \mathrm{C}$ & $80^{\circ} \mathrm{C}$ & $120^{\circ} \mathrm{C}$ \\
Alkali & $\mathrm{C}$ & $0.25 \mathrm{M}$ & $0.50 \mathrm{M}$ & $0.75 \mathrm{M}$ \\
concentration & & & & \\
\hline
\end{tabular}

TABLe 2: Experimental $2^{3}$ factorial design with three center points matrix.

\begin{tabular}{lccccc}
\hline Run & $\begin{array}{c}\text { Run } \\
\text { order }\end{array}$ & $\begin{array}{c}\text { A } \\
\text { time }\end{array}$ & $\begin{array}{c}\text { B } \\
\text { temperature }\end{array}$ & $\begin{array}{c}\text { C alkali } \\
\text { concentration }\end{array}$ & Notation \\
\hline 1 & 4 & - & - & - & $12-40-0.25$ \\
2 & 7 & + & - & - & $36-40-0.25$ \\
3 & 5 & - & + & - & $12-120-0.25$ \\
4 & 3 & + & + & - & $36-120-0.25$ \\
5 & 1 & - & - & + & $12-40-0.75$ \\
6 & 8 & + & - & + & $36-40-0.75$ \\
7 & 6 & - & + & + & $12-120-0.75$ \\
8 & 11 & + & + & + & $36-120-0.75$ \\
9 & 2 & 0 & 0 & 0 & $24-80-0.50$ \\
10 & 9 & 0 & 0 & 0 & $24-80-0.50$ \\
11 & 10 & 0 & 0 & 0 & $24-80-0.50$ \\
\hline
\end{tabular}

concentration $(\mathrm{M})$, such as $12-40-0.25$, that represents 12 hours, $40^{\circ} \mathrm{C}$, and $0.25 \mathrm{M}$, respectively.

2.3. Characterization. The crystal structure of the samples was analyzed by X-ray diffraction (XRD) using a D8 Discover-Bruker X-ray diffractometer with $\mathrm{Cu} \kappa \alpha$ radiation $(\lambda=0.154059 \mathrm{~nm})$ in the low angle mode, with the source fixed angle of $6^{\circ}$. The samples surface morphology and the niobate layer thickness were characterized by scanning electron microscopy (SEM) (TESCAN, Vega 3 operating at $10 \mathrm{kV})$. For the layer thickness measurements, the cross section of each sample was cut in two steps, using a $\mathrm{Ga}$ focalized ion beam; the first one with a current of $3.0 \mathrm{nA}$ followed by the second one, a cleaning step, with $0.5 \mathrm{nA}$ (FEI, Versa 3D DualBeam, electron beam and ion beam operating at $10 \mathrm{kV}$ and $30 \mathrm{kV}$, respectively).

The thickness of the sodium niobate layer, formed on metallic niobium, was measured 5 times for each run condition, using ImageJ, and the synthesis' variables effects were analyzed using the measured values.

2.4. Statistical Analysis. The statistical analysis was performed with the MINITAB software. The effects of the independent variables and the effects due to interactions between the chosen variables were investigated using the analysis of variance (ANOVA), with a 95\% confidence level. The center points allowed the evaluation of the full factorial design model linearity and the experimental errors.

2.5. Bandgap Measurement. The UV-visible diffuse reflectance spectroscopy (DRS) was recorded by an 
ultraviolet-visible spectrophotometer (Thermo, Evolution $300 \mathrm{UV}$-Vis) in the air at room temperature, performed in the wavelength range between 200 and $800 \mathrm{~nm}$ with the Xenon lamp. After the optical analysis, the data were converted according to the Kubelka-Munk equation, intending to obtain the Tauc relation.

\section{Results and Discussion}

3.1. Crystalline Phases Identification. The samples obtained after hydrothermal synthesis (Figure 1) and heat treatment (Figure 2) were analyzed by X-ray diffraction. Figure 1 presents the overall X-ray diffractogram of samples as synthesized, where is possible to observe the peaks in the lower angles, between $10^{\circ}$ and $15^{\circ}$, related to the planes (200), (002), and (202) of $\mathrm{Na}_{2} \mathrm{Nb}_{2} \mathrm{O}_{6} \cdot \mathrm{H}_{2} \mathrm{O}$ (monoclinic, $a=$ 17.114 $\AA, b=5.0527 \AA, c=16.5587 \AA$, and $\beta=113.947^{\circ}$ ), also known as SOMS [25], as well as an amorphous broadband, that could be related to the presence of an amorphous phase and also peaks from the Nb substrate (CCC, $a=3.3007 \AA$ ). As can be seen in Figure 2, the samples obtained at the lower conditions, at $40^{\circ} \mathrm{C}$ and with $\mathrm{NaOH}$ concentration of $0.25 \mathrm{M}$, presented only the characteristic peaks of niobium, independently of the reaction duration. These peaks correspond only to the substrate, showing that, under these conditions, it has not formed the sodium niobate or the layer formed was not thick enough to be detected by XRD. On the contrary, the samples obtained with more concentrated $\mathrm{NaOH}$ solutions and at higher temperatures showed the characteristic peaks of orthorhombic $\mathrm{NaNbO}_{3}$. There are two very similar orthorhombic $\mathrm{NaNbO}_{3}$ structures, with spatial group Pbma (JCPDS: $33-1270$ ) and $\mathrm{P} 2{ }_{1} \mathrm{ma}$ (JCPDS: 77-0873). There are some differences in their ferroelectric behavior; however, it is difficult to distinguish them in XRD patterns as can be seen comparing the diffractograms simulated using Powder Cell 2.3 (Figure 3). Therefore, it was not possible to identify which of them was formed after heat treatment in the samples analyzed in the present work. It was assumed that the crystal structure with space group $\mathrm{P} 2{ }_{1}$ ma (JCPDS: 77-0873) was based on literature reports of similar systems $[5,13,26,27]$.

Peaks attributed to the niobium oxide $\left(\mathrm{Nb}_{2} \mathrm{O}_{5}\right)$ (JCPDS: 30-0873) were also observed in most of the samples. This oxide is probably in the interface between $\mathrm{Nb}$ and niobates nanowires. It could be present on the initial metallic niobium surface in the amorphous form, what explains the amorphous broadband in XRD data of the as-synthesized material, and had crystallized during the heat treatment, what corroborates to the appearance of its XRD peaks after heat treatment at $500^{\circ} \mathrm{C}$, even using a vacuum furnace heating.

3.2. Morphology Characterization. In order to identify the structure formed on metallic niobium after synthesis and after heat treatment steps, the top-view SEM images of the samples were carried out, and the diameters or widths of the 1D nanostructures were measured (Figure 4). At the lowest synthesis conditions, there are few nanowires with small

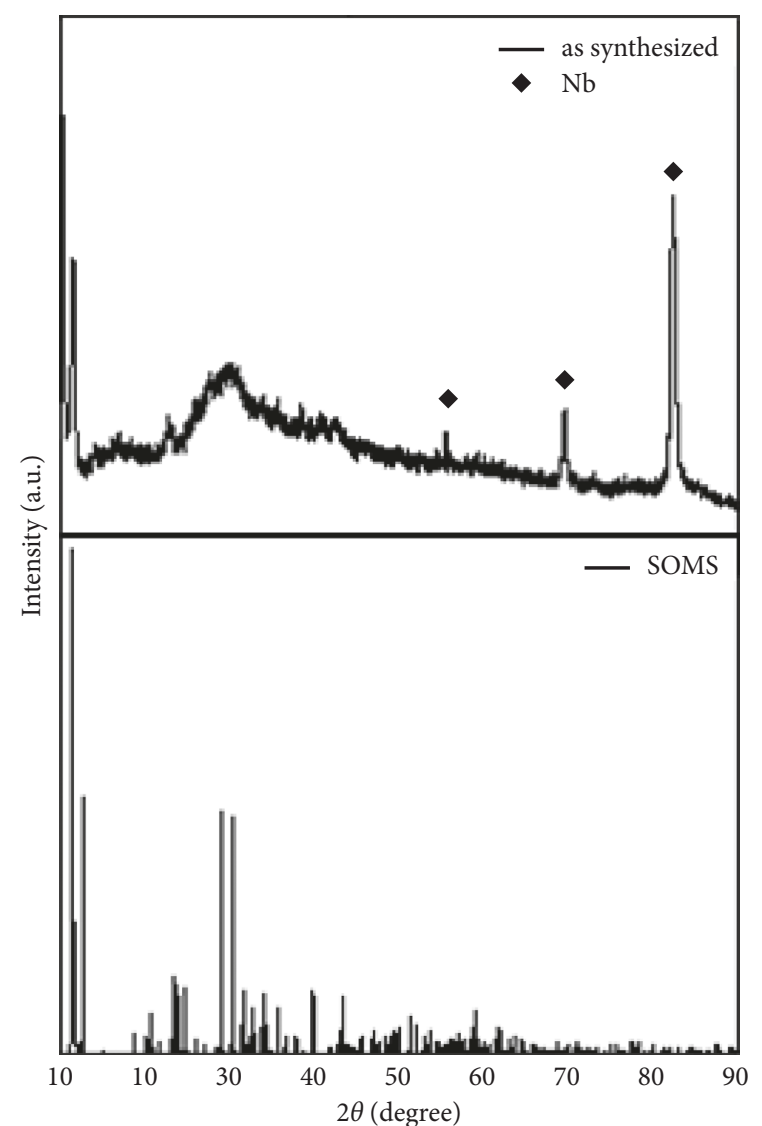

FIGURE 1: X-ray diffraction pattern of the samples as synthesized. The XRD pattern of orthorhombic $\mathrm{Na}_{2} \mathrm{Nb}_{2} \mathrm{O}_{6} \cdot \mathrm{H}_{2} \mathrm{O}$ (SOMS), simulated using CIF code 55415, is depicted in the lower panel.

diameters that can be seen only at higher magnifications. With the increase of $\mathrm{NaOH}$ concentration and reaction time, the surface became more populated with nanowires and it is possible to notice an increase in nanowire diameters (Figure 5).

The samples obtained at the conditions of the experimental design center points $\left(80^{\circ} \mathrm{C}, 24 \mathrm{~h}\right.$, and $\left.0.50 \mathrm{M}\right)$, showed a surface completely populated with nanowires (Figure 5) which showed diameters superior to the ones obtained at $40^{\circ} \mathrm{C}$. And as the temperature increased to $120^{\circ} \mathrm{C}$, nanoribbons began to form. It is possible to notice that the nanoribbons are mainly formed at the $\mathrm{NaOH}$ concentration of $0.75 \mathrm{M}$. Although their widths are larger than the nanowire diameters, reaching the scale of around $300 \mathrm{~nm}$, their thickness is small, of some tens of nanometers.

After heat treatment, the samples were reanalyzed and it was noticed that the nanostructures did not suffer any change in morphology at this step, maintaining their morphology of nanowire or nanoribbon observed after synthesis. The nanowire diameter and the nanoribbon widths were measured again and compared to the values obtained before heat treatment (Figure 4). No significant dimension changes were observed.

3.3. Niobate Layer Thickness Measurement. In order to identify the influence of reaction time, temperature, and 


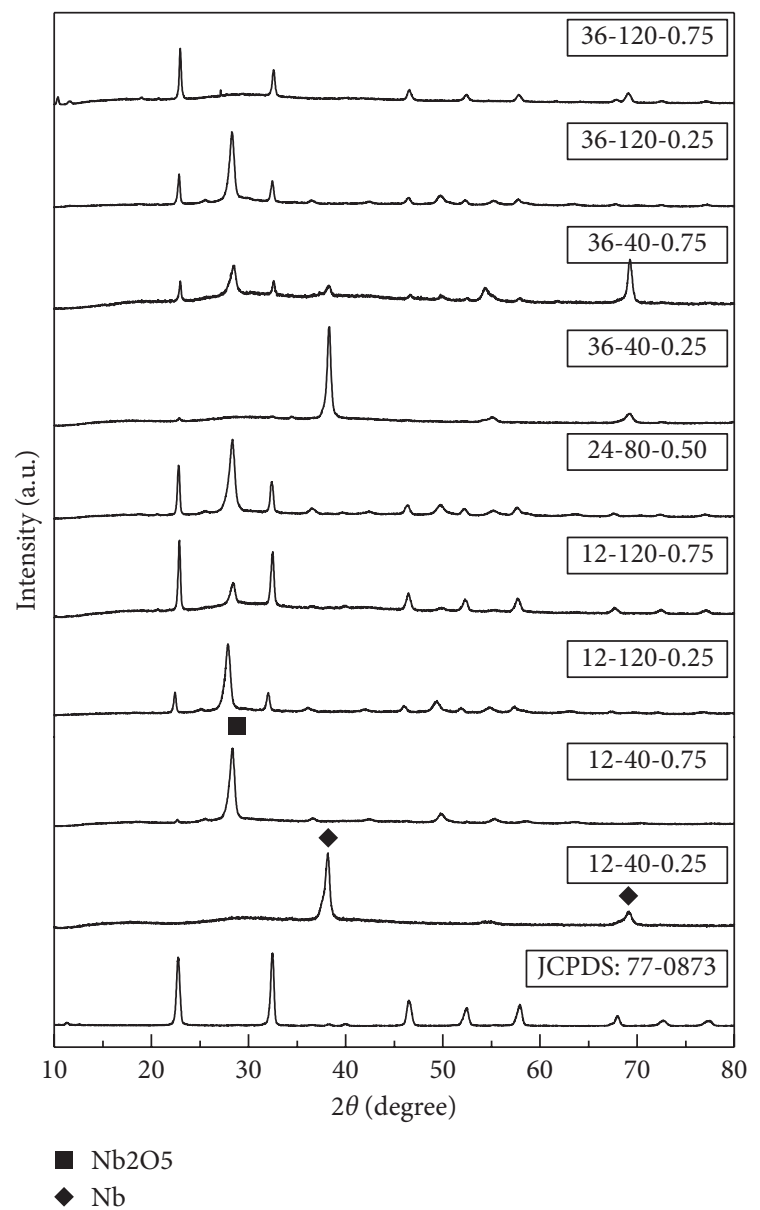

FIgURE 2: X-ray diffraction patterns of the samples synthesized for 12,24 , and 36 hours, at $40^{\circ} \mathrm{C}, 80^{\circ} \mathrm{C}$, and $120^{\circ} \mathrm{C}$, with $\mathrm{NaOH} 0.25 \mathrm{M}$, $0.50 \mathrm{M}$, and $0.75 \mathrm{M}$. The standard pattern of orthorhombic $\mathrm{NaNbO}_{3}$ is depicted in the lower panel.

$\mathrm{NaOH}$ concentration on the sodium niobate layer thickness on metallic niobium, the cross-sectional SEM images were obtained. After heat treatment, the samples were submitted to a focalized ion beam in order to obtain the cross section of the $\mathrm{NaNbO}_{3}$ layer without losing the surface morphology near the cut area, and subsequently, the sodium niobate thickness could be measured.

The variation of the measured nanowire layer thickness with the synthesis conditions can be seen in Figure 6. It was observed that the samples produced at $40^{\circ} \mathrm{C}$ presented the thickness of the niobate layer lower than $2 \mu \mathrm{m}$, while the ones obtained at $80^{\circ} \mathrm{C}$ and $120^{\circ} \mathrm{C}$, with $0.25 \mathrm{M}$ of alkali concentration, presented the thickness between 4 and $6 \mu \mathrm{m}$. The temperature and $\mathrm{NaOH}$ concentration increment, to the values of $120^{\circ} \mathrm{C}$ and $0.75 \mathrm{M}$, led to the thickness increase, reaching the values of $10.44 \mu \mathrm{m}$ and $39.38 \mu \mathrm{m}$, respectively, for the synthesis of 12 and 36 hours.

A typical image of the nanowire layer cross section is shown in Figure 7. One aspect of the cross-sectional SEM images of these samples, which should be emphasized, is that the nanowires and the nanoribbons begin with a small diameter or width near the niobium surface and increase along the layer thickness. Near the niobium surface, it has a

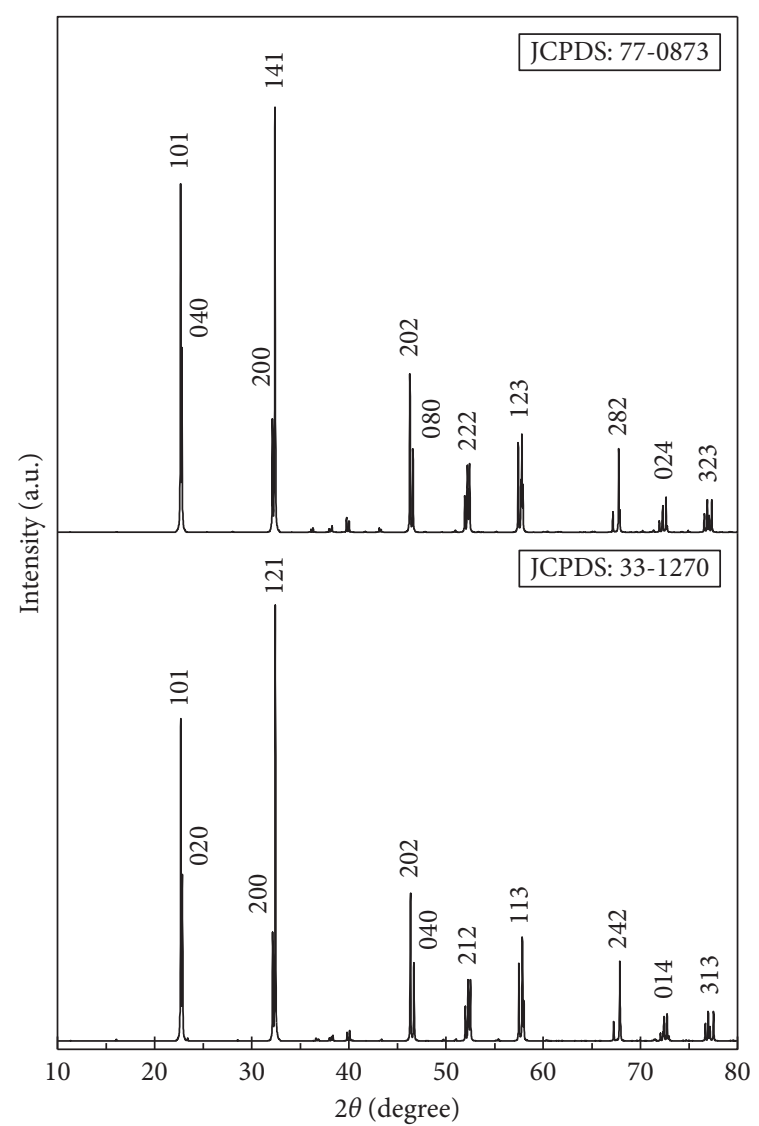

Figure 3: Diffraction patterns simulated orthorhombic $\mathrm{NaNbO}_{3}$ with spatial group Pbma (JCPDS: 33-1270) and P2 ${ }_{1}$ ma (JCPDS: 770873).

large number of little nanowires, which show diameter inferior to that observed at the top-view SEM images. It demonstrates that, at the beginning of the reaction between the metallic niobium and the $\mathrm{NaOH}$ solution, a great number of nuclei have been formed at the metallic surface, and then these nuclei grew epitaxially to form the nanostructures. It seems that these little nanostructures combined themselves along the growth of the niobate layer, showing an increment of the diameter or width of these nanostructures, and that is the reason why with the increment of the synthesis' conditions an increase was observed in the diameter or width of the nanostructures at the top-view images.

The sample with the thickest niobate layer exhibited the formation of cracks and detachment of this layer from the niobium surface, what was confirmed with an analysis of backscattered electrons, as can be seen in Figure 8. This fact is due to an increase in stress accumulated in the structure with the increment of the layer thickness.

3.4. Statistical Analysis. The calculations of the statistical analysis were carried out with $5 \%$ level of significance, generating the analysis of variance (ANOVA) table (Table 3). The resulting $P$ value meant that all three main factors affected the thickness of the sodium niobate layer, as 


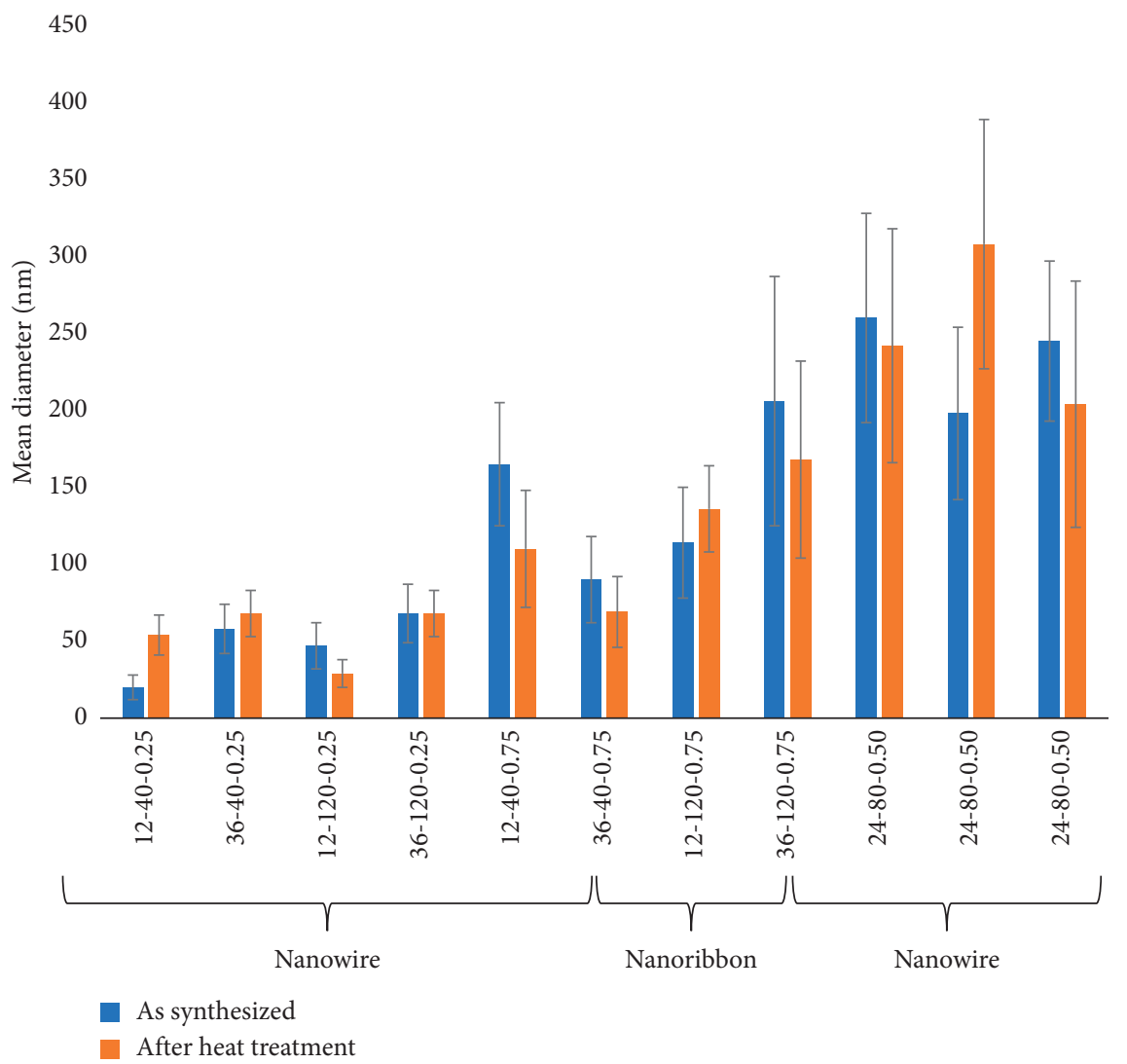

FIGURE 4: Morphology, mean diameter, and standard deviation for each of synthesis conditions, as synthesized, and after heat treatment.

can be seen in Pareto graph (Figure 9). At Figure 9, it is possible to observe the influence order of the synthesis parameter effects, chosen to be studied at the alkali hydrothermal synthesis of nanometric sodium niobate on metallic niobium. Although all of them were statistically significant, the effect of temperature (B) was the most significant, followed by the alkali concentration (C). The influence of two- and three-factor coupled effects were also significant and followed the order $\mathrm{BC}>\mathrm{AB}>\mathrm{ABC}>\mathrm{AC}$. The minor influence in the analyzed factors was due to reaction duration, named as time $(\mathrm{A})$.

A regression analysis of the thickness of the sodium niobate layer, formed on metallic niobium by the hydrothermal route, was obtained by the ANOVA-based full factorial design. The model (Equation (1)) presented an $R$ square of 0.9726 , and an adjusted $R$ square of 0.9685 :

$$
\begin{aligned}
E= & -5.11+0.276 t+0.1070 T+12.62 C-0.00710 t \times T \\
& -1.237 t \times C-0.2446 T \times C+0.03006 t \times T \times C,
\end{aligned}
$$

where $E$ is the thickness of the sodium niobate layer $(\mu \mathrm{m}), t$ is the reaction duration $(\mathrm{h}), T$ is the temperature applied at the reactor $\left({ }^{\circ} \mathrm{C}\right)$, and $\mathrm{C}$ is the $\mathrm{NaOH}$ concentration $(\mathrm{M})$.

The three-factor experimental design showed that the chosen factors influence significantly on the thickness of the sodium niobate layer, and among the chosen ones, the temperature is the most significant. Although it was obtained a high adjusted $R$ square, this design does not represent the experiment so well, as we can see with the high curvature value presented in the analysis of variance. A central composite design could have been used in order to describe the behavior of this experiment with more accuracy. However, it is not possible to change the factor levels in the steepest direction, around the value of the thicker layer found at the design applied, because at these more severe conditions, there is a detachment of the sodium niobate layer from its substrate.

3.5. Bandgap Measurement. The bandgap measurement of the nanostructured sodium niobate supported on metallic niobium was carried out intending to compare the obtained value with the sodium niobate bandgap produced from niobium oxide powder, reported in the literature $[5,8]$. For that purpose, central point sample $\left(0.5 \mathrm{M}, 24 \mathrm{~h}, 80^{\circ} \mathrm{C}\right)$ was chosen after heat treatment that showed nanowire shape niobates.

The bandgap of the nanostructured $\mathrm{NaNbO}_{3}$ supported on niobium substrate has been determined using Tauc's relation $(\alpha h v)^{n}=A(h v-E \mathrm{~g})$, where $\alpha, h, v, A$ and $E \mathrm{~g}$ are the absorption coefficient, Planck constant, light frequency, proportionality constant, and bandgap, respectively. The index $n$ depends on the nature of the material (direct or indirect bandgap), and in the case of sodium niobate, it was used $n=1 / 2$ as, according to the literature, it was considered to have indirect bandgap [28]. 

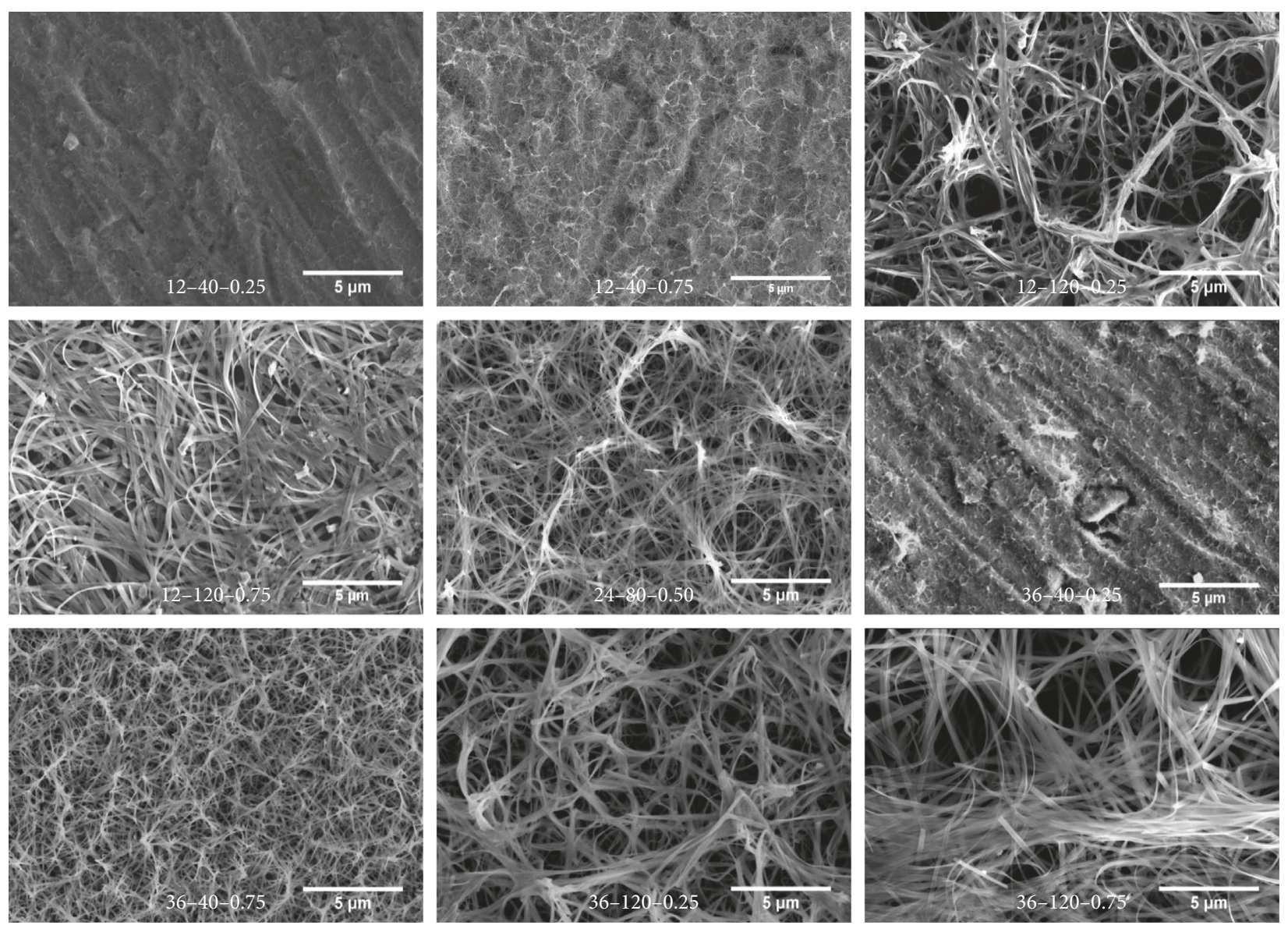

Figure 5: High magnification top-view SEM images of the samples as synthesized (all the samples have the same scale bar).

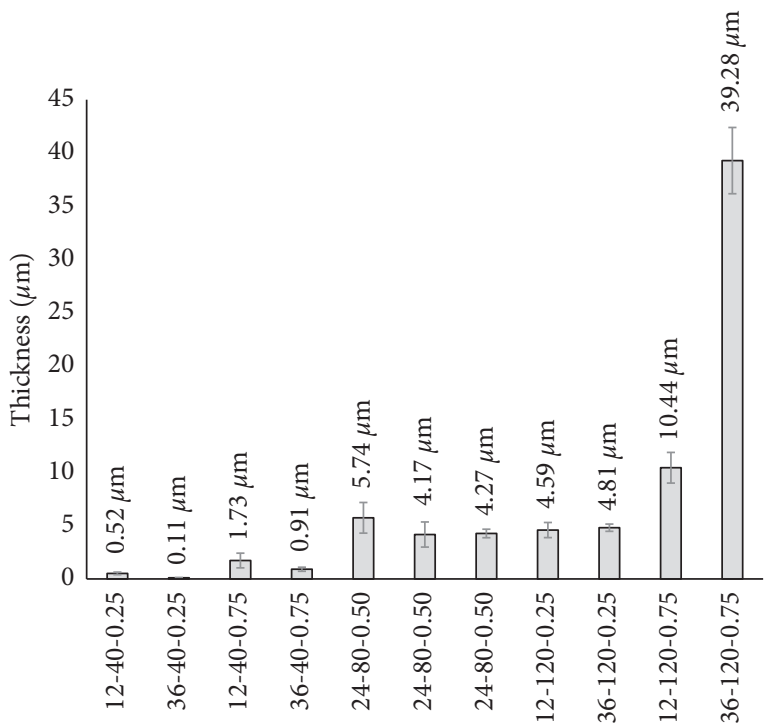

Figure 6: The thickness of the sodium niobate layer measured at each synthesis conditions and the respective standard deviations.

By extrapolating the linear portion of the Tauc plot to zero, a bandgap value of approximately $3.34 \mathrm{eV}$ is obtained (Figure 10). This bandgap is comparable to the values of the bandgap of $\mathrm{NaNbO}_{3}$ reported in the literature, for the

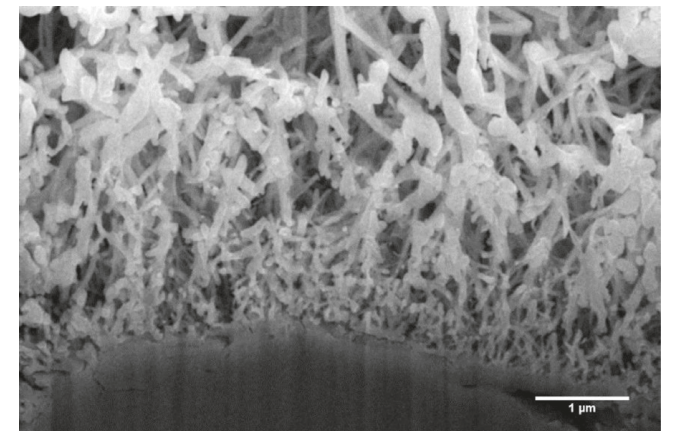

FIgURE 7: Cross-sectional SEM images of $\mathrm{NaNbO}_{3}$ synthesized at $80^{\circ} \mathrm{C}$, for $24 \mathrm{~h}$ with $\mathrm{NaOH}$ concentration of $0.50 \mathrm{M}$ after heat treatment, presenting the increase of the nanowires diameter along the layer thickness.

nanostructured $\mathrm{NaNbO}_{3}$ bandgaps produced from $\mathrm{Nb}_{2} \mathrm{O}_{5}$, demonstrating that the initial source does not influence the bandgap obtained $[5,8,18]$. This bandgap value shows its potential application as a photocatalyst activated in UV range.

\section{Conclusions}

The influence of hydrothermal synthesis conditions on 1D sodium niobate produced from metallic niobium substrate 


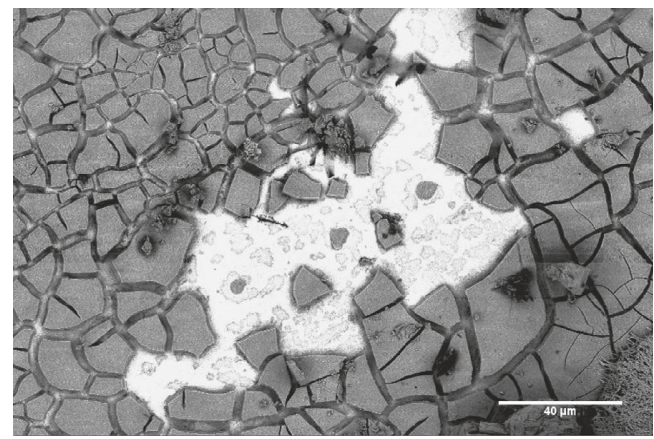

Figure 8: SEM image of a crack region on the surface of the sample synthesized at $120^{\circ} \mathrm{C}$ for $36 \mathrm{~h}$ with $\mathrm{NaOH}$ concentration of $0.75 \mathrm{M}$ after heat treatment.

TABle 3: Analysis of variance (ANOVA) of the $2^{3}$ full factorial design.

\begin{tabular}{|c|c|c|c|c|c|}
\hline Source & $\mathrm{df} *$ & Sum of squares & Mean square & $F$ value & $P$ value \\
\hline Model & 8 & 6167.54 & 770.94 & 535.29 & 0.00 \\
\hline Time, A & 1 & 489.88 & 489.88 & 340.14 & 0.00 \\
\hline Temperature, B & 1 & 1961.53 & 1961.53 & 1361.95 & 0.00 \\
\hline Alkali concentration, $\mathrm{C}$ & 1 & 1111.24 & 1111.24 & 771.57 & 0.00 \\
\hline $\mathrm{AB}$ & 1 & 579.66 & 579.66 & 402.48 & 0.00 \\
\hline $\mathrm{AC}$ & 1 & 490.93 & 490.93 & 340.87 & 0.00 \\
\hline $\mathrm{BC}$ & 1 & 909.42 & 909.42 & 631.44 & 0.00 \\
\hline $\mathrm{ABC}$ & 1 & 520.43 & 520.43 & 361.35 & 0.00 \\
\hline Curvature & 1 & 104.45 & 104.45 & 72.52 & 0.00 \\
\hline Error & 46 & 66.25 & 1.44 & & \\
\hline Total & 54 & 6233.79 & & & \\
\hline
\end{tabular}

$* \mathrm{df}=$ degree of freedom.

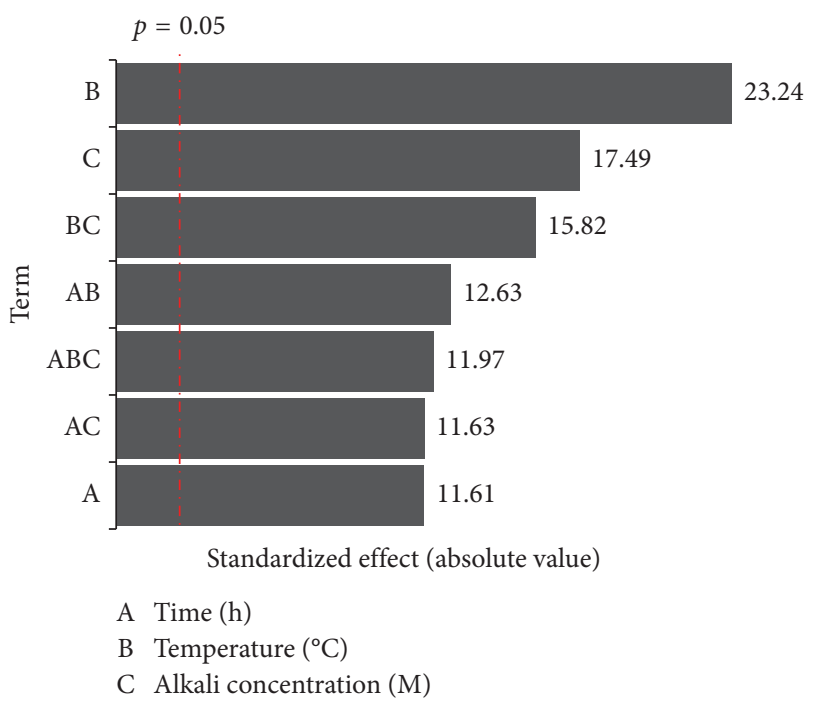

FIGURE 9: Graph of Pareto showing the variables' effects on the thickness of the sodium niobate layer based on the experimental design.

was studied. The variation of temperature, reaction duration, and $\mathrm{NaOH}$ solution concentration affected not only the $1 \mathrm{D}$ niobate layer thickness but also the nanostructures morphology (nanowires or nanoribbons) and dimensions.

The as-synthesized niobate is monoclinic $\mathrm{Na}_{2} \mathrm{Nb}_{2} \mathrm{O}_{6} \cdot \mathrm{H}_{2} \mathrm{O}$, and after heat treatment, it transforms into orthorhombic
$\mathrm{NaNbO}_{3}$ without changing the nanostructures morphology and dimensions. XRD analysis indicated that as-synthesized samples also contain amorphous niobium oxide that crystalizes after heat treatment.

The cross-sectional image analysis observation showed that the sodium niobate $1 \mathrm{D}$ nanostructures begin to grow from the niobium surface with small diameters, and they seem to join each other increasing the diameter along the layer thickness.

At the mildest synthesis conditions, the sodium niobate on the top of the layer has a nanowire form, with diameters of a few dozens of nanometers, while at the more severe conditions; they have a nanoribbon form that reached a mean width of $260 \mathrm{~nm}$.

In relation to the sodium niobate thickness layer, the mildest conditions produced very thin layers of few tenths of micrometers, while the more severe conditions produced thicker layers that reached a mean value of almost $40 \mu \mathrm{m}$.

Among the studied factors of the experimental design, the temperature and the alkali concentration used at the alkali hydrothermal route to synthesize the sodium niobate on niobium showed effects with more influence on the thickness of the sodium niobate layer than the reaction duration, although it has also demonstrated that it is statistically significant to the thickness layer.

The nanostructured sodium niobate supported on metallic niobium presented a bandgap value of $3.34 \mathrm{eV}$, similar to the ones reported for the sodium niobate 


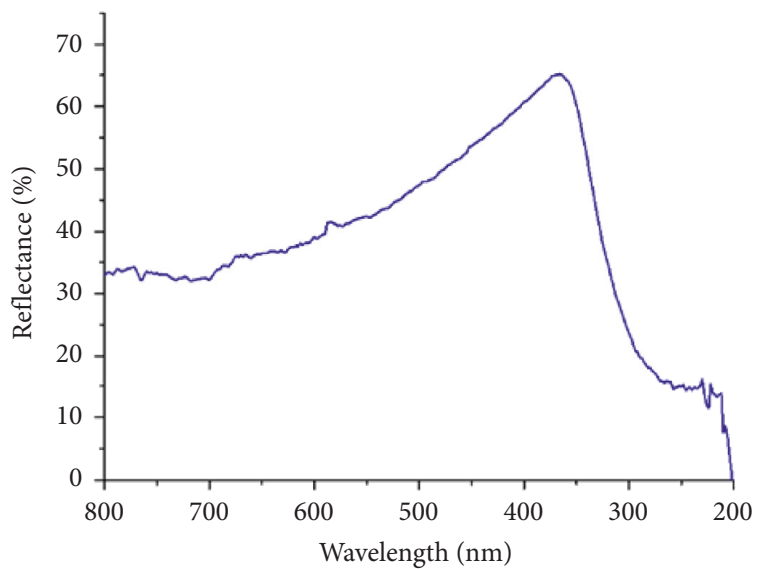

(a)

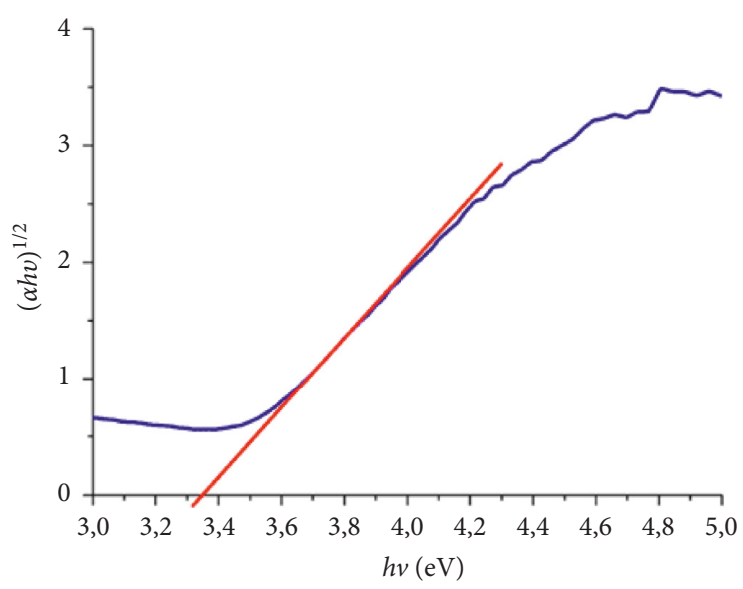

(b)

FIGURE 10: Diffuse reflection spectra of the nanostructured sodium niobate (a) and the extrapolation of the $\mathrm{NaNbO}_{3}$ bandgap in the Tauc plot (b).

produced from the niobium oxide. This bandgap value indicates the potential application of the system $\mathrm{NaNbO}_{3} /$ $\mathrm{Nb}$ in photocatalysis.

\section{Data Availability}

The data used to support the findings of this study are available from the corresponding author upon request.

\section{Conflicts of Interest}

The authors declare that there are no conflicts of interest regarding the publication of this paper.

\section{Acknowledgments}

This study was financed in part by the National Council for Technological and Scientific Development (CNPq) and by the Coordenação de Aperfeiçoamento de Pessoal de Nível Superior-Brasil (CAPES)_Finance Code 001.

\section{Supplementary Materials}

The supplementary material file submitted along the manuscript is a graphical abstract. (Supplementary Materials)

\section{References}

[1] S. Y. Wu, W. Zhang, and X. M. Chen, "Formation mechanism of $\mathrm{NaNbO} 3$ powders during hydrothermal synthesis," Journal of Materials Science: Materials in Electronics, vol. 21, no. 5, pp. 450-455, 2010.

[2] R. Grange, F. Dutto, and A. Radenovic, "Niobates nanowires: synthesis, characterization and applications," in NanowiresImplementations and Applications, InTech, London, UK, 2011.

[3] R. Godley, D. Starosvetsky, and I. Gotman, "Bonelike apatite formation on niobium metal treated in aqueous $\mathrm{NaOH}$," Journal of Materials Science: Materials in Medicine, vol. 15, no. 10, pp. 1073-1077, 2004.

[4] X. J. Wang, Y. C. Li, J. G. Lin, Y. Yamada, P. D. Hodgson, and C. E. Wen, "In vitro bioactivity evaluation of titanium and niobium metals with different surface morphologies," Acta Biomater, vol. 4, no. 5, pp. 1530-1535, 2008.

[5] S. Singh and N. Khare, "Coupling of piezoelectric, semiconducting and photoexcitation properties in $\mathrm{NaNbO}_{3}$ nanostructures for controlling electrical transport: realizing an efficient piezo-photoanode and piezo-photocatalyst," Nano Energy, vol. 38, pp. 335-341, 2017.

[6] H. Pan, G. S. Zhu, X. L. Chao, L. L. Wei, and Z. Yang, "Properties of $\mathrm{NaNbO}_{3}$ powders and ceramics prepared by hydrothermal reaction," Materials Chemistry and Physics, vol. 126, no. 1-2, pp. 183-187, 2011.

[7] P. Li, S. Ouyang, G. Xi, T. Kako, and J. Ye, "The effects of crystal structure and electronic structure on photocatalytic $\mathrm{H}_{2}$ evolution and $\mathrm{CO}_{2}$ reduction over two phases of perovskitestructured $\mathrm{NaNbO}_{3}$," Journal of Physical Chemistry C, vol. 116, no. 14, pp. 7621-7628, 2012.

[8] H. Shi, T. Wang, J. Chen, C. Zhu, J. Ye, and Z. Zou, "Photoreduction of carbon dioxide over $\mathrm{NaNbO}_{3}$ nanostructured photocatalysts," Catalysis Letters, vol. 141, no. 4, pp. 525-530, 2011.

[9] Q. Liu, Y. Chai, L. Zhang, J. Ren, and W. L. Dai, "Highly efficient $\mathrm{Pt} / \mathrm{NaNbO}_{3}$ nanowire photocatalyst: its morphology effect and application in water purification and $\mathrm{H}_{2}$ production," Applied Catalysis B: Environmental, vol. 205, pp. 505-513, 2017.

[10] P. J. Holmquist, "Synthetische Studien über die Perowskitund Pyrochlormineralien," Bulletin of the Geological Institution of the University of Upsala, vol. 3, pp. 181-266, 1896.

[11] H. Zhu, Z. Zheng, X. Gao et al., "Structural evolution in a hydrothermal reaction between $\mathrm{Nb}_{2} \mathrm{O}_{5}$ and $\mathrm{NaOH}$ Solution : from $\mathrm{Nb}_{2} \mathrm{O}_{5}$ grains to microporous $\mathrm{Na}_{2} \mathrm{Nb}_{2} \mathrm{O}_{6} 2 / 3 \mathrm{H}_{2} \mathrm{O}$ fibers and $\mathrm{NaNbO}_{3}$ cubes," Journal of the American Chemical Society, vol. 128, no. 7, pp. 2373-2384, 2006.

[12] T. Ke, H. Chen, H. Sheu et al., "Sodium niobate nanowire and its piezoelectricity sodium niobate nanowire and its piezoelectricity," Journal of Physical Chemistry C, vol. 112, no. 24, pp. 8827-8831, 2008.

[13] S. Ji, H. Liu, Y. Sang, W. Liu, G. Yu, and Y. Leng, "Synthesis, structure, and piezoelectric properties of ferroelectric and antiferroelectric $\mathrm{NaNbO}_{3}$ nanostructures," CrystEngComm, vol. 16, no. 32, pp. 7598-7604, 2014. 
[14] G. Li, T. Kako, D. Wang, Z. Zou, and J. Ye, "Synthesis and enhanced photocatalytic activity of $\mathrm{NaNbO}_{3}$ prepared by hydrothermal and polymerized complex methods," Journal of Physics and Chemistry of Solids, vol. 69, no. 10, pp. 2487-2491, 2008.

[15] A. Yu, J. Qian, L. Liu, H. Pan, and X. Zhou, "Surface sprouting growth of $\mathrm{Na}_{2} \mathrm{Nb}_{2} \mathrm{O}_{6} \cdot \mathrm{H}_{2} \mathrm{O}$ nanowires and fabrication of $\mathrm{NaNbO}_{3}$ nanostructures with controlled morphologies," Applied Surface Science, vol. 258, no. 8, pp. 3490-3496, 2012.

[16] K. Zhu, Y. Cao, X. Wang, L. Bai, J. Qiu, and H. Ji, "Hydrothermal synthesis of sodium niobate with controllable shape and structure," CrystEngComm, vol. 14, no. 2, pp. 411-416, 2012.

[17] I. C. M. S. Santos, L. H. Loureiro, M. F. P. Silva, and A. M. V. Cavaleiro, "Studies on the hydrothermal synthesis of niobium oxides," Polyhedron, vol. 21, pp. 2009-2015, 2002.

[18] E. S. Baeissa, "Photocatalytic degradation of malachite green dye using $\mathrm{Au} / \mathrm{NaNbO} 3$ nanoparticles," Journal of Alloys and Compounds, vol. 672, pp. 564-570, 2016.

[19] S. L. Skjærvø, K. H. Wells, S. Sommer et al., "Rationalization of hydrothermal synthesis of $\mathrm{NaNbO}_{3}$ by rapid in situ timeresolved synchrotron X-ray diffraction," Crystal Growth and Design, vol. 18, no. 2, 2018.

[20] K. Byrappa and T. Adschiri, "Hydrothermal technology for nanotechnology," Progress in Crystal Growth and Characterization of Materials, vol. 53, pp. 117-166, 2007.

[21] M.-A. Einarsrud and T. Grande, "1D oxide nanostructures from chemical solutions," Chemical Society Reviews, vol. 43, no. 7, pp. 2187-2199, 2014.

[22] G. Canu and V. Buscaglia, "Hydrothermal synthesis of strontium titanate: thermodynamic considerations, morphology control and crystallisation mechanisms," CrystEngComm, vol. 19, no. 28, pp. 3867-3891, 2017.

[23] L. Li, C. Liu, Y. Qiu, N. Mitsuzak, and Z. Chen, “The influence of the hydrothermal temperature and time on morphology and photoelectrochemical response of $\alpha-\mathrm{Fe}_{2} \mathrm{O}_{3}$ photoanode," Journal of Alloys and Compounds, vol. 696, pp. 980-987, 2017.

[24] Y. Özeren, E. Mensur-Alkoy, and S. Alkoy, "Sodium niobate particles with controlled morphology synthesized by hydrothermal method and their use as templates in KNN fibers," Advanced Powder Technology, vol. 25, no. 6, pp. 1825-1833, 2014.

[25] M. Nyman, A. Tripathi, J. B. Parise, R. S. Maxwell, and T. M. Nenoff, "Sandia octahedral molecular sieves (SOMS): structural and property effects of charge-balancing the MIVsubstituted $(\mathrm{M}=\mathrm{Ti}, \mathrm{Zr})$ niobate framework," Journal of the American Chemical Society, vol. 124, no. 8, pp. 1704-1713, 2002.

[26] B. Jaffe, W. R. Cook Jr., and H. Jaffe, "Applications of Piezoelectric Ceramics,” Piezoelectric Ceramics, vol. 3, pp. 271$280,1971$.

[27] J. H. Jung, M. Lee, J. Il Hong et al., "Lead-free $\mathrm{NaNbO}_{3}$ nanowires for a high output piezoelectric nanogenerator," ACS Nano, vol. 5, no. 12, pp. 10041-10046, 2011.

[28] P. Li, S. Ouyang, Y. Zhang, T. Kako, and J. Ye, "Surfacecoordination-induced selective synthesis of cubic and orthorhombic NaNbO3 and their photocatalytic properties," Journal of Materials Chemistry A, vol. 1, no. 4, pp. 1185-1191, 2013. 


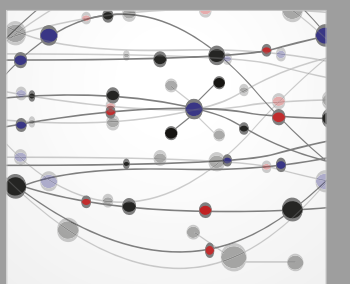

The Scientific World Journal
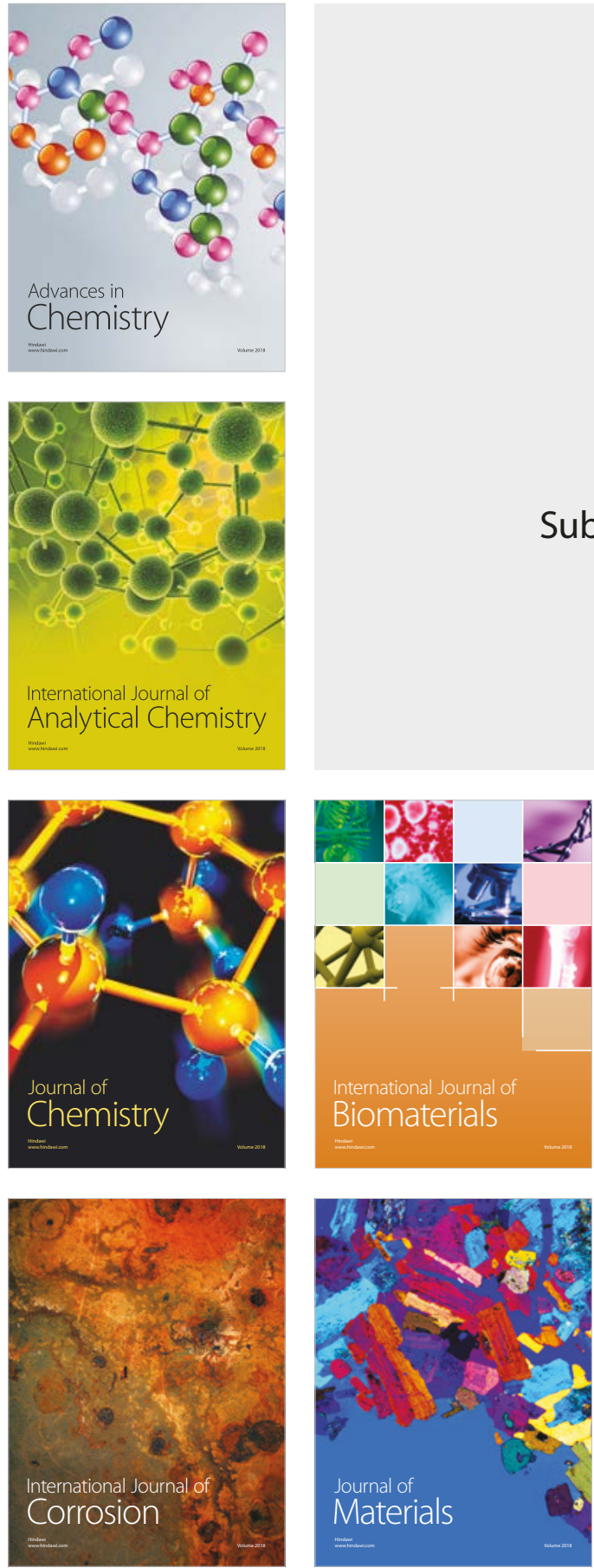

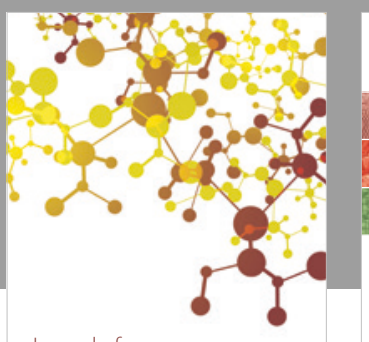

Journal of

Applied Chemistry
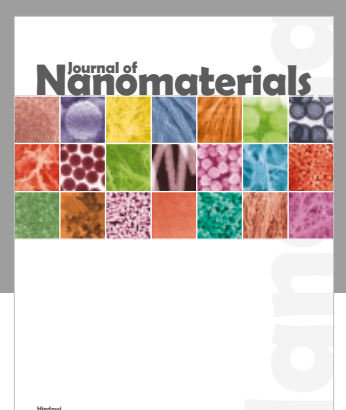

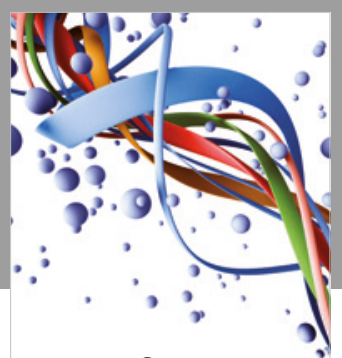

Scientifica

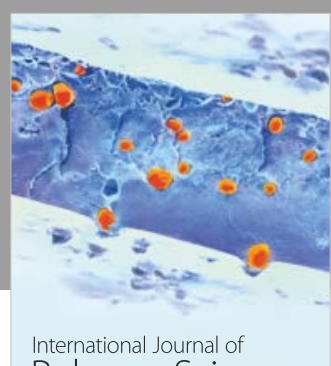

Polymer Science

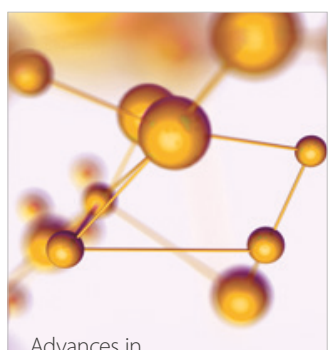

Physical Chemistry
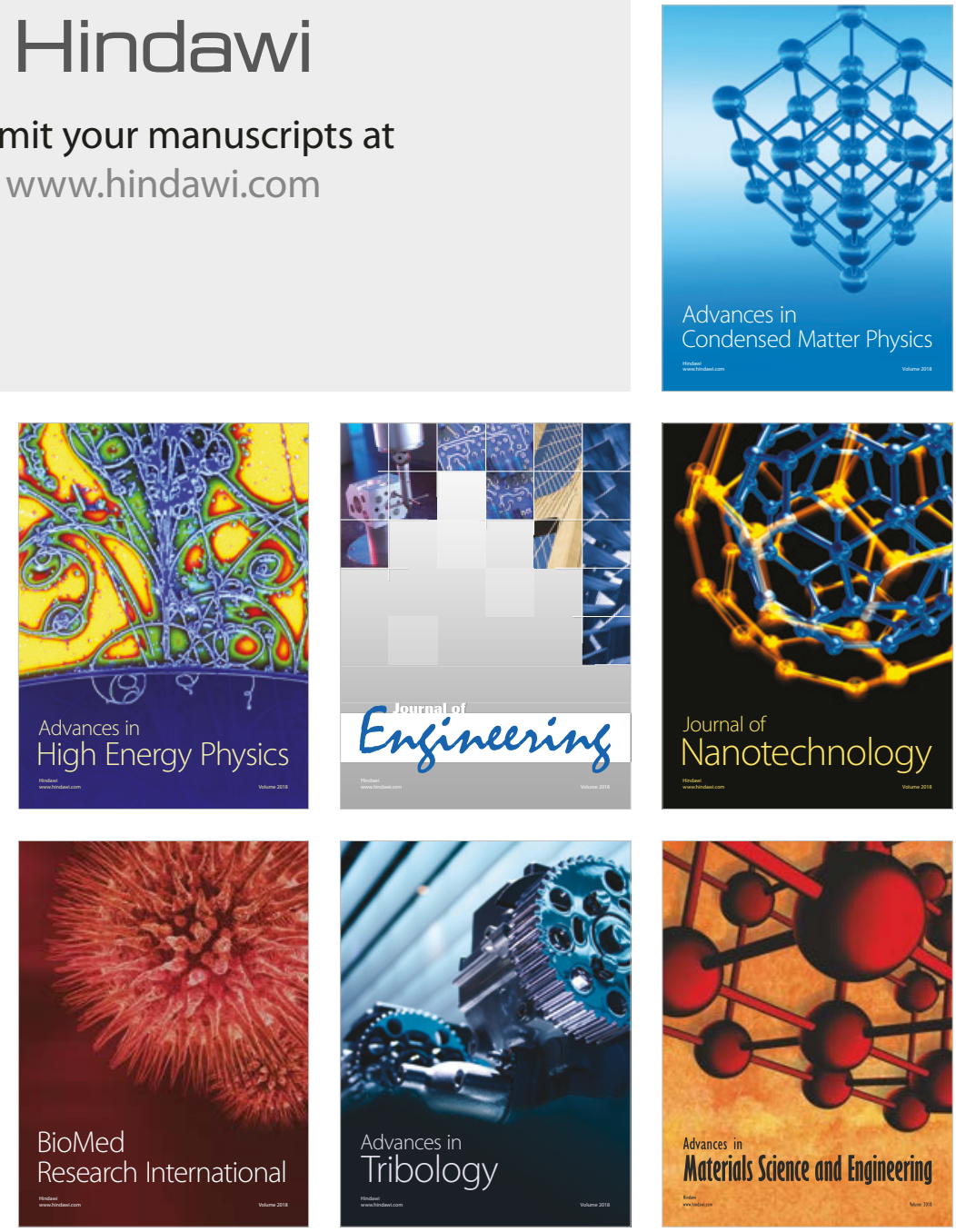